\title{
Awareness of parents of hearing-impaired children about the importance of speech-language therapeutic interventions
}

\author{
N azia Sheikh ${ }^{1}$, Bareera Saeed ${ }^{2}$, Atia ur Rehman ${ }^{3}$ \\ ${ }^{1}$ M S Scholar, ${ }^{2}$ Senior L ecturer, ${ }^{3}$ Assistant Professor, D epartment of $\mathrm{H}$ ealth Professional $\mathrm{T}$ echnologies, Faculty of Allied $\mathrm{H}$ ealth Sciences, $\mathrm{T}$ he \\ $U$ niversity of $L$ ahore, $L$ ahore, Pakistan \\ Correspondence to: Bareera Saeed, E mail: bareerasaeedwarraich@gmail.com
}

\begin{abstract}
Background: The importance of parental involvement of hearing-impaired children in their child's speech therapy cannot be denied. The current study aimed to determine parental awareness and involvement in the Speech-language therapeutic interventions of hearing-impaired children.

Subjects and methods: This was a cross-sectional study design, and a purposive sampling technique was used. Data were collected from 45 parents (male=32, female=13) of hearing-impaired children whose children received speech therapy from special education centers and schools of G ujranwala. T he duration of the study was nine months, from June 2019 to February 2020. A related questionnaire was developed with the literature, and expert opinions (Cronbach's $\alpha=0.894$ ) were used to assess parental awareness and involvement in speech therapeutic interventions. $D$ ata entered and analyzed by SPSS version 23. D escriptive statistics were used to describe demographic variables (age, gender) of the participants. Frequency and percentage were used to access the awareness and involvement of the parents of hearing-impaired children.

Results: Parental awareness survey showed that a total of 15 (33.3\%) parents, both mother and father, strongly agreed, and $24(53.3 \%)$ agreed that speech therapy would be beneficial for their child. And results related to parents' involvement showed that $21(46.7 \%)$ parents, both mother, and father, agreed, and $15(33.3 \%)$ strongly agreed on their child's active involvement in speech therapy plans.

Conclusions: The study concluded that most parents understand the importance of parental awareness and involvement in the therapeutic intervention of hearing-impaired children.

Keywords:
\end{abstract}

H earing impairment, Parental awareness, Parental involvement, T herapeutic interventions

\section{INTRODUCTION}

Speech therapy is essential for hearing-impaired children for successful inclusion in the mainstream society for communication. Speech therapy of hearingimpaired children required active parental involvement, awareness, and understanding regarding therapeutic interventions. ${ }^{1}$ Each speech therapist shares information with clients and careers and consequently necessity custom an employed corporation with patients and domestic supporters as acceptable. Theory and practices encouraged parental involvement for the hearing-impaired child's early education and therapeutic interventions. ${ }^{2} \mathrm{H}$ earing deficiency is the greatest widespread, long-lasting situation afterward hypertension and stiffness. The person consequently undergoes equally bodily and communally. ${ }^{3,4} \mathrm{At}$ present, there has been an essential reorientation of the technique in which speaking and phonological counselors and other specialists effort with the relatives

C onflict of interest: T he authors declared no conflict of interest exists.

Citation: Sheikh N, Saeed B, Rehman A, Awareness of parents of hearingimpaired children about the importance of speech-language therapeutic interventions. J Fatima Jinnah M ed U niv. 2021; 15(2): 63-66.

D OI: https://doi.org/10.37018/VAU 04413 of their pediatric clienteles. ${ }^{5}$ In the process of speech therapy, the effectiveness depends upon the contribution from the child itself and the contribution of time and resources on the part of parents. The theory behind the parental participation at school and special institutions is rummage-sale to discover the parental participation in speaking treatment as the main aim of both the institutions is the same, i.e., to enhance the education level of the kid. ${ }^{6}$ In the case of speech therapy, parental participation can be anticipated by several happenings completed by the paternities in a speaking rehabilitation period. ${ }^{7} \mathrm{P}$ aternal participation is precise significant to create a fruitful speaking rehabilitation. ${ }^{8} \mathrm{~A}$ study was conducted to examine the efficiency of parental applied home-based programs in enabling the growth of youngsters' speaking and phonological services and assess the charge-efficiency and possibility of this facility distribution process. Results showed that home-based programs could develop a youngster's speaking and linguistic services and are supplementary real than no interference. T he home-based programs are a charity with significant amount duties and straight parental exercise. ${ }^{9}$ Another study explored parental involvement awareness and 
aspects that might influence paternal participation. The result showed that paternal envelopment had been exposed to deliver valuable consequences when used in combination with speaking rehabilitation. ${ }^{10}$ In Kailila speaking rehabilitation institute, paternal envelopment in youngsters' speaking rehabilitation is a responsibility that has been connected with parentages in the method of prescribed contracts. According to speaking rehabilitators in K ailila rehabilitation institute, there are parentages who motionless have not completed their duty. Results showed that mother and father have optimistic awareness related to their participation though one of the counselors has a dissimilar awareness with the mother and father. The recurrence of 60 minutes at the homespun, quantity of kids, familial participation, and incitement from counselors all impact paternal participation in a kid's therapeutic treatment. ${ }^{11} \mathrm{~T}$ he aim of this study was to determine parental awareness and involvement regarding their children's speech-language impairment and required intervention programs.

\section{SUBJ ECTS AND METHODS}

The cross-sectional study was conducted on 45 parents (32 fathers, 13 mothers) of hearing impaired-children. A purposive sampling technique was used. The O penE pi, V ersion 3, open-source calculator was used to calculate the sample size using the proportion formula. T he sample was selected from special education centers and special education schools of Gujranwala, where hearing-impaired children were taking speech therapy. On the basis of inclusion criteria, parents were selected as a sample whose children were enrolled and receiving therapy in special education centers and schools of the Gujranwala division for one year. Parents of children with speech-language delay, cerebral palsy, learning disability, and mentally challenged chromosomal abnormalities and comorbidity conditions were omitted. D ata were collected from parents of hearingimpaired children through the self-designed questionnaire based on the awareness and involvement of parents in their child's speech therapeutic intervention from Government Special Education Centers and Schools of $G$ ujranwala. The questionnaire was developed based on literature and expert opinion. Q uestionnaire reliability was tested and (C ronbach's $\alpha$ ) was (.894). Before starting the data collection procedure, departmental permission was taken. The letter was sent to the institutional head from where data was collected and the signed permission letter for data collection. Basic parameters of parental awareness and involvement were studied. The duration of the study was nine months, from June 2019 to February 2020. Data entered and analyzed by SPSS version 23. Descriptive statistics were used to describe demographic variables (age, gender, siblings) of the participants. Frequency and percentage have been presented in all items of the questionnaire.

\section{RESULTS}

Results show that among 45 participants, 32(71.1\%) were fathers, and $13(28.9 \%)$ were mothers. Table 1 describes parental awareness about the therapeutic intervention of hearing-impaired children. T otal 15 (33.3\%) respondents (parents) out of 45 strongly agreed, 24 respondents (53.3\%) agree that speech therapy is beneficial for their child. Eighteen respondents $(40.0 \%)$ agree about awareness of child's degree and types of hearing loss, 15 respondents (33.3\%) disagree. T wenty-four respondents (53.3\%) agree about skilled enough in your child's disorder and their diagnosis. $(46.7 \%)$ disagree about our knowledge is enough for our child's speech therapy strategies.

Table 1. F requency and percentages of the parental questionnaire

\begin{tabular}{|c|c|c|c|c|c|}
\hline \multirow[b]{2}{*}{ Q uestions: Parental awareness } & \multicolumn{5}{|c|}{ Responses } \\
\hline & $\begin{array}{l}\text { Strongly } \\
\text { D isagree }\end{array}$ & D isagree & $\mathrm{N}$ eutral & Agree & $\begin{array}{c}\text { Strongly } \\
\text { Agree }\end{array}$ \\
\hline Is speech therapy beneficial for your child? & $1(2.2)$ & $2(4.4)$ & $3(6.7)$ & $24(53.3)$ & $15(33.3)$ \\
\hline Are you fully aware of your child's degree and types of hearing loss? & $1(2.2)$ & $15(33.3)$ & $9(20.0)$ & $18(40.0)$ & $2(4.4)$ \\
\hline Is your knowledge enough for your child's speech therapy strategies? & $4(8.9)$ & $21(46.7)$ & $6(13.3)$ & $12(26.7)$ & $2(4.4)$ \\
\hline Do environmental factors influence the performance of your child? & $1(2.2)$ & $5(11.1)$ & $3(6.7)$ & $21(46.7)$ & $15(33.3)$ \\
\hline Being a parent, are you aware of interventions and prognosis of hearing-Impaired children? & $2(4.4)$ & $24(53.3)$ & $6(13.3)$ & $9(20.0)$ & $4(8.9)$ \\
\hline \multicolumn{6}{|l|}{ Parental Involvement } \\
\hline D o you actively participate in setting speech therapy plans for your child? & $1(2.2)$ & $5(11.1)$ & $3(6.7)$ & $21(46.7)$ & $15(33.3)$ \\
\hline D o you ask for the home plan after a session? & $3(8.9)$ & $10(22.2)$ & $7(15.6)$ & $21(46.7)$ & $4(8.9)$ \\
\hline Do you work with your child on therapy goals at home? & $3(6.7)$ & $11(24.4)$ & $5(11.1)$ & $22(48.9)$ & $4(8.9)$ \\
\hline Do you give regular feedback regarding your child's home plan to your speech therapist? & $1(2.2)$ & $15(33.3)$ & $5(11.1)$ & $19(42.2)$ & $5(11.1)$ \\
\hline D o you share your child's therapy plan with your other family members? & $3(6.7)$ & $15(33.3)$ & $7(15.6)$ & $13(28.9)$ & $7(15.6)$ \\
\hline Do you demand a W ritten Progress Report of your child from the therapist? & $2(4.4)$ & $14(31.1)$ & $5(11.1)$ & $11(24.4)$ & $13(28.9)$ \\
\hline D o you help out to set goals for your child's therapeutic interventions with your child's therapist? & $1(2.2)$ & $11(24.4)$ & $7(15.6)$ & $23(51.1)$ & $3(6.7)$ \\
\hline Do you cooperate with your child's Speech therapist? & $2(4.4)$ & $10(22.2)$ & $7(15.6)$ & $17(37.8)$ & $9(20.0)$ \\
\hline
\end{tabular}


T wenty respondents $(44.4 \%)$ agree about problems facing regarding child's speech-language hearing assessment. T welve respondents (26.7\%) agree about feeling that child has sufficient speech skills for their day-to-day functioning, 20 respondents $(44.4 \%)$ disagree. T wenty-one respondents $(46.7 \%)$ agree about feeling that environmental factors influence the performance of the child. T able 2 also showed parental involvement in therapeutic intervention of hearingimpaired children. T otal 21 respondents $(46.7 \%)$ agree about the active participation in speech therapy plans of your child.21 respondents (46.7\%) agree about asking for the home plan after the session. T wenty-two respondents $(48.9 \%)$ agree about working with the child on therapy goals at home. $\mathrm{N}$ ineteen respondents $(42.2 \%)$ agree about regular feedback regarding the child's home plan to the speech therapist. Thirteen respondents $(28.9 \%)$ agree about sharing the child's therapy plan with other family members. Thirteen $(28.9 \%)$ respondents were demanding a written progress report of children from the therapist. A total of 23 respondents $(51.1 \%)$ agree about the help out to set goals for the child's therapeutic interventions with the child's therapist.

\section{DISCUSSION}

The current study is grounded on the evidence that speech and language therapy is beneficial when parents are aware and involved in therapeutic implementations. In this regards the opinion of parents holds special importance. ${ }^{12}$ According to $\mathrm{N}$ amasivayam and coworkers, mother and father participation is a significant part of speech language therapy because it produces positive changes in therapy outcomes and attitudes towards therapy. ${ }^{13}$ Parents and Speechlanguage pathologists must focus on some fundamental factors affecting parental involvement in the therapeutic program and how to increase it. ${ }^{14} \mathrm{~T}$ he study result showed that most parents have been aware of and showed their maximum involvement towards therapists and their children's therapeutic interventions. ${ }^{15} \mathrm{~T}$ hese results are similar to a previous report describing parents reports that they worked with their children weekly and monthly. ${ }^{16}$ Present study showed that $41.5 \%$ of participants (parents) strongly agreed with parental awareness and involvement items. O ne study found that $(74.5 \%)$ parents showed interest and agreement in therapeutic intervention of hearing-impaired children. ${ }^{17}$ Current study found that $31.9 \%$ of participants (parents) reported neutral responses at parental awareness and involvement items of the questionnaire. $T$ he findings were consistent with a prior study showing that 50 parents out of 65 were significantly active in the therapeutic intervention and worked hearing-impaired child's therapy goals at home. Due to social class differences, the remaining 15 parents did not show interest and no awareness about therapeutic intervention. ${ }^{18}$ In the study, $9.1 \%$ of participants reported disagreement, and $4 \%$ of participants reported strong disagreement with parental awareness and involvement items of the questionnaire. O ne previous study assessed the parent's and other family members' involvement in speech therapeutic interventions of hearing-impaired children. ${ }^{19} \mathrm{~T}$ heir finding showed that parents, especially mothers, are more concerned about participation in treatment, but only $5 \%$ of parents disagree about parental involvement, and 10\% of mothers feel stress when their children do not speak instead of therapeutic intervention. ${ }^{19}$

\section{CONCLUSIONS}

This study concluded that most parents reported strongly agree and agree responses regarding awareness and parental involvement in the therapeutic intervention. This study highlights parental involvement, awareness in therapeutic interventions.

\section{REFERENCES}

1. Fudala JB, England $G, G$ anoung L. U tilization of parents in a speech correction program. Except Child. 1972 Jan; 38(5):40712.

2. L aw J, van der G aag A, H ardcastle W J, Beckett D J, M acG regor A, Plunkett C. Communication Support needs: a review of the literature. Scottish Executive; 2007.

3. Rakap S, Rakap S. Parent-implemented naturalistic language interventions for young children with disabilities: A systematic review of single-subject experimental research studies. Educ Res Rev. 2014 D ec 1;13:35-51.

4. Kleeck AV. Potential cultural bias in training parents as conversational partners with their children who have delays in language development. Am J Speech Lang Pathol. 2018 Jan;3(1):67-78.

5. Van Gent $T$, Goedhart AW, Hindley PA, Treffers PD. Prevalence and correlates of psychopathology in a sample of deaf adolescents. J Child Psychol Psychiatr. 2007 Sep;48(9):950-8.

6. Fairgray $L$, Purdy $S$. Benefits of speech $\&$ language therapy for hearing impaired children. V olta Rev. 2008;102(1):5-24.

7. Baggett HC, Duchin JS, Shelton W, Zerr DM, H eath J, Ortega-Sanchez IR, T iwari T. T wo nosocomial pertussis outbreaks and their associated costs_King County, W ashington, 2004. Infect Control Hosp Epidemiol. 2007 M ay;28(5):537-43.

8. Franck $L S, C$ allery $P$. Re-thinking family-centred care across the continuum of children's healthcare. $\mathrm{C}$ hild $\mathrm{C}$ are $\mathrm{H}$ ealth D ev. 2004 M ay;30(3):265-77. 
9. M eadow-O rlans K P, Sass- L ehrer M, M ertens D M . Parents and their deaf children: T he early years. G allaudet U niversity Press; 2016.

10. Tosh R, Arnott W, Scarinci N. Parent-implemented home therapy programmes for speech and language: A systematic review. Int J L ang Commun D isord. $2017 \mathrm{M}$ ay;52(3):253-69.

11. W atts Pappas N, M CAllister L, M CL eod S. Parental beliefs and experiences regarding involvement in intervention for their child with speech sound disorder. Child Lang Teach Ther. 2016 J un;32(2):223-39.

12. Campbell M G. Investigating parental views of involvement in pre-school speech and language therapy. Int J Lang Commun Disord. 2000 J an 1;35(3):391-405.

13. Jane G, T unjungsari H. Parents and Speech Therapist Perception of Parental Involvement in K ailila T herapy C enter, Jakarta, Indonesia. J E duc Pract. 2015;6(8):111-7.

14. N amasivayam AK, J ethava $V$, Pukonen $M, H$ uynh A, G oshulak $D, K$ roll $R$, van $L$ ieshout $P$. Parent-child interaction in motor speech therapy. D isabil Rehabil. 2018 J an 2;40(1):104-9.
15. Crais ER, Roy VP, Free K. Parents' and professionals' perceptions of the implementation of family-centered practices in child assessments. Am J Speech Lang Pathol. 2006. 3;15 (4):365-77.

16. Pappas NW, MCLeod S, M cAllister L, MCK innon DH. Parental involvement in speech intervention: A national survey. Clin Linguist Phon. 2008 J an 1;22(4-5):335-44.

17. M illard SK, N icholas A, Cook FM . Is parent-child interaction therapy effective in reducing stuttering? J Speech $\mathrm{L}$ ang $\mathrm{H}$ ear Res. 2008.

18. Zaidman-Zait A, M ost T, T arrasch R, H addad-eid E, Brand D. $T$ he impact of childhood hearing loss on the family: M others' and fathers' stress and coping resources. J Deaf Stud Deaf E duc. 2016 Jan 1;21(1):23-33.

19. Sugden E, Baker E, M unro N, W illiams AL. Involvement of parents in intervention for childhood speech sound disorders: a review of the evidence. Int J Lang Commun Disord. 2016 N ov;51(6):597-625. 